\title{
COVID-19 and the opportunity to design a more mindful approach to learning
}

\author{
Conrad Hughes ${ }^{1}$
}

Published online: 29 July 2020

(C) UNESCO IBE 2020

\begin{abstract}
The industry of modern schooling leads to surface learning of exaggeratedly voluminous curricula and excessively high-stakes assessments that instrumentalize the pursuit of knowledge. In order to return to a more mindful, authentic, and humanly paced approach, disruption from the present model is needed. Paradoxically, the COVID-19 pandemic might be the catalyst that will bring this about.
\end{abstract}

Keywords Learning · Assessment · COVID-19 · Curriculum

The fundamental purpose of education is to improve the human condition. Education leads to a longer, better life, a higher income, and, at a public level, a better society (Wiliam 2016). However, the assessment of learning is a thorny issue, and, in its most extreme forms, it often leads to excessive mental pressure and everything but a better life. While baseline assessment and assessment with a formative purpose allow for growth, assessment with a summative purpose is fundamentally a judgment after learning, based on a performance. Millions of children throughout the world sit examinations, entrance tests, and interviews and enter high-stakes competitions to see who will come out at the end and in which order. This creates an emotional and psychological burden that can become unbearable.

The idea that students should be graded against each other goes back to the Gaussian bell curve that still informs most assessment design: students are assessed, at the end of their learning, so as to be arranged in the lower or top quartile, the top 1 percent, or, simply, the mean. Norm-referencing originated in the Industrial Revolution and subsequent massification of schooling: with the reforms of the 1800s leading to a universal education, the scale and implications of schooling became so large that assessment protocols started

Conrad Hughes

conrad.hughes@ecolint.ch

1 International School of Geneva, La Grande Boissière, 62, Route de Chêne, 1208 Geneva, Switzerland 
to act as filters, ensuring that fewer and fewer students would rise to the top of a steep hierarchy of grades, schools, universities, jobs, and titles built to protect elites.

This worldview has led us to top tier universities refusing entry to students with maximum entry examination points, boasting acceptance levels of well under 10\% (Paramita 2020) and taking placement offers off the table when high school students are a single point below what is requested. As higher education becomes globalized and increasingly massified and a small circle of ranked and branded universities become the dream destinations of millions of candidates every year, the pressure mounts even more to the point where it is no longer compatible with the deep purposes of an education.

What are the implications and spin-offs of this unsustainable situation? The first is teaching to the test: instead of viewing high school as a period of intellectual growth and curiosity, risk-taking, and self-discovery, it becomes a morbid curriculum-crunching experience to take students to the best possible test scores (Sellgren 2017; Marope et al. 2018, p. 8). It is not only the students who suffer from this narrowing of the curriculum, but the teachers too who have to grapple with multiple levels of accountability and deliverables (Will 2019).

To make matters worse, there is a huge amount of information to plough through in most curricula. Dylan Wiliam states: "there is no doubt that there's far too much stuff in our curriculum-I've wondered about why this is, and my conclusion is that curriculum developers cannot bear the thought that any children might have spare time on their hands" (cited in Lough 2020). The ancient Greek scholé was a place for gentle, peripatetic reflection, away from the noise and distractions of everyday life. According to Herodotus, the Persians managed to whittle their education down to three elegant principles: "horsemanship, archery, and telling the truth" (Herodotus 1954, p. 1.136); the liberal arts of the Middle Ages and the early Renaissance contained only seven constructs.

However, in a post-Enlightenment world, with the specialization of labor, the influence of the post-Cold War Space Race on STEM curriculum development, the mounting realization of the importance of the arts, the need to design bilingual or even multilingual programs, the need to integrate new technologies into learning, the ever-increasing content of humanities, science, and mathematics courses, curriculum now suffers from the so-called "crowded garage effect" (Gotlieb 2015)—David Perkins' complaint that "new content is continually added but rarely removed from the curriculum". Therefore, the curriculum has become a monstrous, heavy, and daunting Leviathan that students must carry like Atlas holding up the world. It is not much better for teachers who are called upon ceaselessly to map and document content and delivery. Students and teachers head into each weekend exhausted by testing, marking, hours of curriculum coverage, and little time for breathing, deep thinking, reflection, and digestion.

And the examinations that come at the end of it all are a type of bulimic paradox of this content-heavy trauma: students belch out what they can in a race against the clock and forget most of what they have learned soon after (Baulkman 2014).

\section{COVID-19 disruption as an opportunity}

Much has been written about the COVID-19 pandemic's nefarious effects on learning: children have fallen behind; gaps in wealth and opportunity have been exacerbated; the economic fallout indicates a very difficult pathway ahead (Lewin 2020); and the muchneeded social interaction of schooling has been violently disrupted. 
However, there have been a number of positive outcomes: community-based approaches and partnerships within the private sector have been activated for the common good (Iyengar 2020), and the lockdown slowed down the pollution of the planet and forced deep reflection away from "business as usual".

\section{Less is more}

Ning and Corcoran (2020) have pointed out that when students learn online, good practice is to reduce contact time. Schools that take heed of this advice during the lockdown allow their students a chance to breathe and, for once, not to have to rush through the curriculum. By creating this space, levels of tension and exhaustion are mitigated.

Some schools have not only modified the curriculum but have replaced examinations with alternative assessments such as projects and viva voces (Hughes 2020). These allow for some of the stress and surface learning that is typical of examinations to be replaced by more serene, less competitive thinking. This approach allows students more time and scope of expression to show what they can do. Projects and vivas, unlike written examinations. are closer to the types of assignments and assessments that young people will be carrying out in their adult lives.

With an entire learning system interrupted, it is necessary to get to the core of learning, which is to say essential concepts and big understandings. A program that does this by focusing on threshold concepts and threshold knowledge so as to consciously identify and reinforce those ideas that are central in any given episteme, is the Universal Learning Programme, developed by the International School of Geneva and UNESCO International Bureau of Education (IBE). Students design "universal understandings" as syntheses of what they have learned (McConville 2020).

Because online learning is so taxing on concentration and energy levels, many schools have compensated for this by reducing or even stopping homework, which research suggests is ineffective in the primary years and has debatable advantages in secondary schooling anyway (Pinsker 2019).

\section{Conclusion}

The COVID-19 pandemic is reminding educators, as they step back from a heavily charged curriculum ending with high-stakes examinations, that future systems need to be mindful of the entire ecosystem of learning and to consider student, teacher, family, and community wellness. Furthermore, now is an opportunity to break away from some of the contentheavy assessments and processes that have turned much of schooling into a highly competitive instrumentalization of knowledge. By concentrating on deep learning and life-worthy knowledge rather than surface learning and test-worthy knowledge, tomorrow's approaches will move closer to the overarching and enduring purpose of an education: to gently sow the seed of lifelong learning for public good.

This implies not only slowing down and making less aggressive the approach to knowledge at schools but also rethinking entry criteria to universities at the level of admissions. Universities must design mechanisms that allow for a deeper appreciation of candidates than test scores and grade averages. Differentiated, project-based assessments and individual narratives will lead to a more meaningful, fair, and nuanced approach. Universities are already being 
forced to do this as examinations have been cancelled and alternative evidence for student learning is being sought by admission officers.

As administrators, teachers, and students prepare for future disruptions, it will be everyone's responsibility not to reduce the curriculum but to synthesize it so that what is learned is essential and powerful. Gaps in learning are bad, but a gap of time to take stock might be a good thing.

\section{References}

Baulkman, J. (2014). First-year college students forget up to 60 percent of material they learned [in] high school. University Herald. https:/www.universityherald.com/articles/10125/20140625/first-year-college-studentsforget-up-to-60-percent-of-material-they-learned-high-school.htm.

Gotlieb, R. (2015). Future wise: Educating our children for a changing world by David Perkins. Learning \& the Brain. https://www.learningandthebrain.com/blog/future-wise-educating-our-children-for-a-changingworld-by-david-perkins/.

Herodotus, (1954). The histories (A. de Sélincourt, Trans.). London: Penguin.

Hughes, C. (2020). Will COVID-19 spell the end for exams? World Economic Forum. https://www.wefor um.org/agenda/2020/06/will-covid-19-spell-the-end-for-exams/.

Iyengar, R. (2020). Education as the path to a sustainable recovery from COVID-19. Prospects. https://doi. org/10.1007/s11125-020-09488-9.

Lewin, K. M. (2020). Contingent reflections on coronavirus and priorities for educational planning and development. Prospects. https://doi.org/10.1007/s11125-020-09480-3.

Lough, C. (2020). Dylan Wiliam: "Immoral" to teach "too full" curriculum. TES. https://www.tes.com/news/ dylan-wiliam-immoral-teach-too-full-curriculum.

Marope, M., Griffin, P., \& Gallagher, C. A. (2018). Transforming teaching, learning, and assessment. Geneva: UNESCO IBE.

McConville, A. (2020). GCSEs: Is a system not dictated by exams possible? TES. https://www.tes.com/magaz ine/article/gcses-system-not-dictated-exams-possible.

Ning, A., \& Corcoran, B. (2020). How China's schools are getting through COVID-19. EdSurge. https://www. edsurge.com/news/2020-04-20-how-china-s-schools-are-getting-through-covid-19.

Paramita, P. (2020). 2020 college acceptance rates: The latest admissions trends. Ingeniusprep. https://ingen iusprep.com/blog/2020-college-acceptance-rates/.

Pinsker, J. (2019). The cult of homework. The Atlantic. https://www.theatlantic.com/education/archive/2019/03/ homework-research-how-much/585889/.

Sellgren, K. (2017). Teaching to the test gives "hollow understanding". BBC. https://www.bbc.com/news/educa tion-41580550.

Wiliam, D. (2016). Assessment for learning: Why, what and how. Cambridge Assessment for Learning keynote. https://dylanwiliam.org/Dylan_Wiliams_website/Papers_files/Cambridge\%20AfL\%20keynote.doc.

Will, M. (2019). Teaching in 2020 vs. 2010: A look back at the decade. Education Week. https://www.edwee k.org/ew/articles/2019/12/11/teaching-in-2020-vs-2010-a-look.html.

Publisher's Note Springer Nature remains neutral with regard to jurisdictional claims in published maps and institutional affiliations.

Conrad Hughes is campus and secondary principal and teaches philosophy at the International School of Geneva, La Grande Boissière, Switzerland. He holds a PhD (University of the Witwatersrand, South Africa) and an EdD (University of Durham, UK). He is a member of the Educational Advisory Board for the University of the People (Pasadena, US) and a UNESCO IBE Senior Fellow. His research interests include twenty-first-century education, critical thinking, international education, and assessment. He is the author of numerous articles in peer-reviewed journals and, as director of education at the International School of Geneva, he led the publication of UNESCO IBE's Guiding Principles for Learning in the 21st Century. Dr. Hughes' previous publications include Understanding Prejudice and Education: The Challenge for Future Generations; English A: Literature for the International Baccalaureate; and Educating for the Twenty-First Century: Seven Global Challenges. 